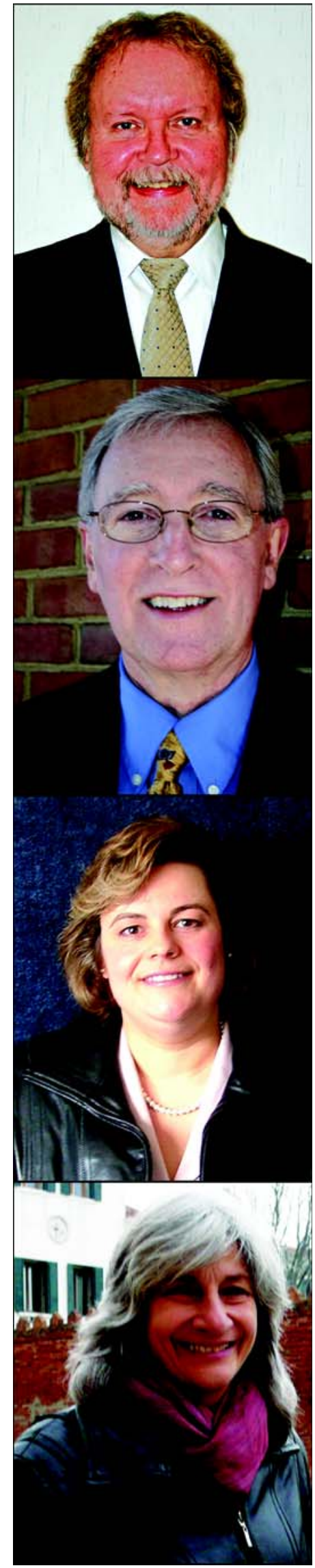

F. Don Nidiffer, PhD; L. G. Leake, MEd; Tina M. Trudel, PhD; Dorothy Palanza, MFA

\section{Vocational and community integration for military servicemembers and civilians with traumatic brain injuries at Paintings \& Prose: A combined art gallery and bookstore}

Key elements of successful independence in life are securing and maintaining a job and meaningfully engaging in satisfying activities-working and playing. The ability to be productive, however, requires a complex set of skills that are often lost when a brain injury occurs. Unfortunately, military personnel involved in the Iraq and Afghanistan wars often experience traumatic brain injuries (TBIs) from enemy explosives [1]. Brain injuries from explosive blasts from car bombs, improvised explosive devices, the more lethal explosively formed projectiles, and rocket-propelled grenades occur so frequently as to be considered the signature injury of these wars [2]. In addition, military personnel and civilians will also experience brain injuries from other mechanisms, such as motor vehicle accidents, falls from heights, training accidents, and violent encounters (e.g., fights, robberies) in unsafe situations in the United States as well as in foreign countries.

These difficulties, along with others, are addressed in a real-world environment at Virginia NeuroCare (VANC) and its innovative art gallery and used bookstore, Paintings \& Prose. VANC, a civilian-operated, Department of Defense-funded brain injury services program for military servicemembers with brain injuries, is located in Charlottesville, Virginia. Founded in 1999, VANC is an active member of the Defense and Veterans Brain Injury Center (DVBIC) (www.dvbic.org), a national network of providers with several missions: (1) to evaluate and treat TBI in military servicemembers; (2) to provide brain injury education to family, friends, individuals with brain injuries, and the general public; (3) to track all returning military personnel from overseas deployments to Iraq and Afghanistan; (4) to develop clinical standards of care for providing brain injury services for the military; and (5) to implement research on TBI and posttraumatic stress disorder (PTSD).

Gainful employment is a major marker for a successful recovery following TBI [3]. However, basic skills required for even entry-level jobs can often be lost as a result of TBI [4]. Accordingly, TBI rehabilitation focuses not only on reducing typical problems with behavioral disinhibition or initiation but also on redeveloping social skills, basic problem-solving, safety awareness, and the abilities required for a specific job. Poor coping strategies such as substance abuse; social interaction styles that include passivity or anger; and basic problems with deficit awareness, disorganization, and lacking goal-directed behaviors often preempt the veteran's ability to get or sustain a job following a brain injury. While often not the primary focus of rehabilitation, the development of avocational, recreational, and leisure skills is also a critical component in enhancing quality of life after TBI. 


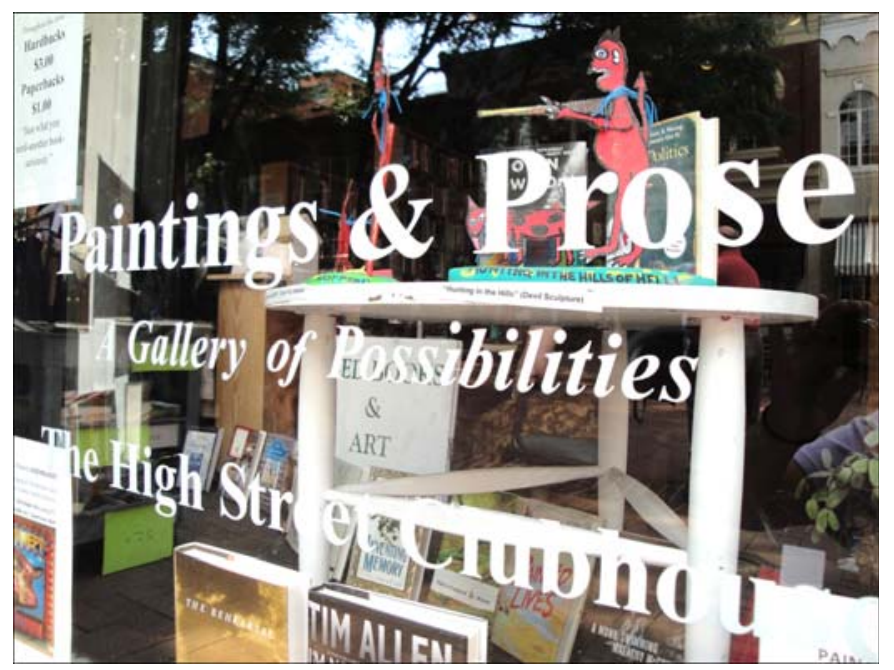

Painting \& Prose: A Gallery of Possibilities, located on the downtown pedestrian mall in Charlottesville, Virginia, is a Defense and Veterans Brain Injury Center-funded brain injury rehabilitation site providing therapy and vocational training through an integrated art gallery and used bookstore.

Active Duty military and veterans from all branches of service, as well as civilians, are treated at VANC. From the point of injury, the process of evaluation, treatment, and rehabilitation begins. As military servicemembers move through the beginning stages of acute medical care and stabilization (or in some mild TBI cases, are recognized some time afterward), the question of what percentage of recovery will likely occur is raised. Some servicemembers return to their units and do well. Often in the National Guard and Reserve Units, servicemembers return to their civilian jobs and can be effectively treated as outpatients. In other cases, while the need for hospitalization has passed, success in returning to jobs and community integration has not been fully achieved. This gap, which sometimes exists but is often not recognized in the traditional stages of rehabilitation recovery, results in less than optimal outcomes and diminished quality of life. VANC seeks to fill this gap.

VANC allows individuals in this category to live, temporarily, in the Grove House, an actual home setting in the community, while receiving intensive therapy from a comprehensive interdisciplinary clinical team, including a medical director (James R. Clark, MD), neuropsychologists (Tina M. Trudel, PhD,
DVBIC Principal Investigator and Site Director, and Jeffrey T. Barth, PhD, ABPP-CN, DVBIC Research Coordinator), a behavioral clinical psychologist (F. Don Nidiffer, PhD, ABMPP, DVBIC Coprincipal Investigator and Program Manager), a substance abuse counselor (Jim Hardiman, MSW, LCSW, CSAC, DVBIC Regional Care Coordinator), a physical therapist (Dennis Yutchishen, PT), occupational therapists (Kellie Doolittle, OTR/L, and Barbara L. Nidiffer, OT/L), a speech and language cognitive therapist (Gary Levine, MS, CCC-SLP), a case manager (Kathleen Bennett, MSW), a vocational specialist (L. G. Leake, MEd), a TBI-education coordinator (Adrienne Rumph, RN, DVBIC Education Coordinator) and a consulting psychiatrist (Joseph David, MD). Support staff includes an Admissions Coordinator (Debbie Henry) and a Quality Assurance/Quality Improvement Coordinator (Elizabeth Bouldin-Clopton). Providing 24/7 direct supervision, including meals and staff-administered medications, VANC may be considered a "finishing" school for community reentry, representing the final intensive treatment stage in the recovery from TBI. By providing close guidance in group and individual therapy situations, therapists can help individuals in the program gradually regain independence in selfcare, cognitive, emotional, behavioral, social, family, vocational, and community functioning. Coping skills and leisure activity development are further enhanced by music and art therapies, substance abuse counseling, PTSD individual and group sessions, and animalfacilitated therapy (via service dogs that have been shown to have a positive influence in the treatment of PTSD). Assistive technologies, such as global positioning system devices and personal digital assistants, also help foster independent community integration. Selected soldiers have also been involved in redeveloping their driving skills by participating in the University of Virginia Driving Simulation Program.

Additional therapeutic efforts are advanced via a horticultural program set in a greenhouse that was built with funds raised with 100 percent community donations in a small gymnasium at the Grove House, a converted garage. A structured schedule of individual and group therapies are provided Monday through Friday, 9 am to $3 \mathrm{pm}$, with continued individual 
therapy sessions and community activities following. Therapy programs are integrated into the 24-hour schedule of the Grove House (Darlene Bevard, House Manager), a residential house and transitional apartment with no more than 10 servicemembers in the program, allowing greater amounts of individualized attention 24 hours a day.

Therapeutic leaves of absence may occur on the weekends or throughout the individual's stay in the program, allowing an evaluation of progress in the program through feedback gained from family and friends in the home community. Based on this feedback, programmatic treatment modifications are made as needed on a person's return to the program. The average length of stay at the Grove House is 3 months, with progress rather than third-party reimbursement dictating discharge plans.

Paintings \& Prose also has volunteers from two civilian programs that are part of VANC. The High Street Clubhouse is a Department of Rehabilitative Services (DRS) program that works with TBI civilians and veterans in a day program format (Leigh Wion, RT, Director, and Nikki White and Judy Robinson, Unit Coordinators). The Clubhouse is physically connected to the art gallery/bookstore and provides an opportunity for prevocational trials and social integration for club members in a closely supervised environment. The other civilian program is Breezy Hill (Doug Desper, House Manager), a long-term residential house for individuals who require support services. This home, located in Weyer's Cave, Virginia, provides additional volunteers for the bookstore on an intermittent basis.

One of the most unique features of the VANC program is the emphasis on the servicemembers' return to work, whether on Active Duty or as a civilian. At the current time, over 25 vocational positions are available for civilian and military participants in the program, with new sites created according to the vocational interests of individuals in the program. VANC works with the Director of the University of Virginia Curry School of Education Personnel and Career Development Center to help determine the best vocational selection for each person in the program. Vocational trials are available exclusively for

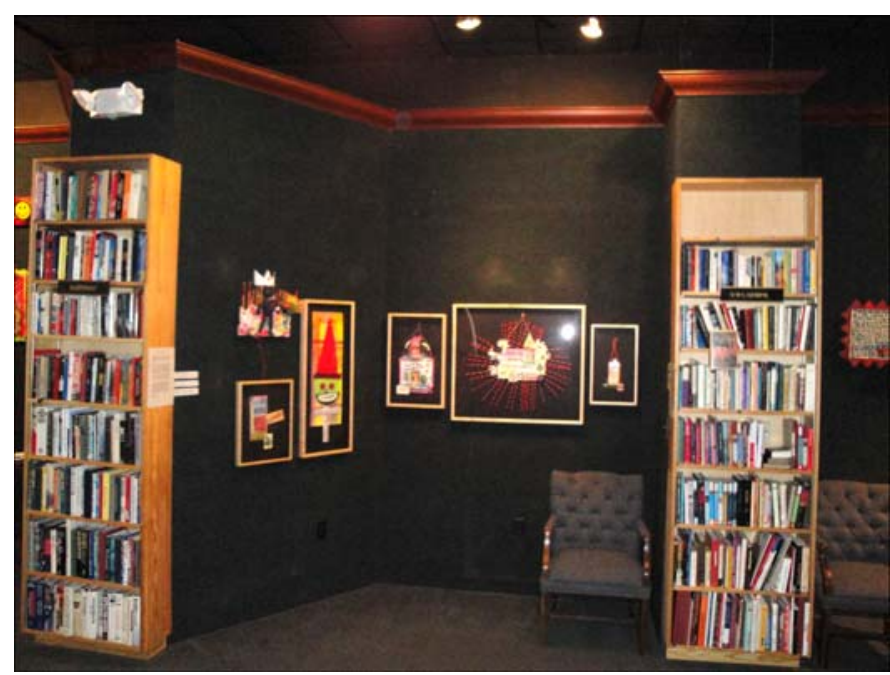

In one of the seven exhibit areas at Paintings \& Prose, a recent art show featured work of Dr. Richard Bay, professor of art and brain surgery survivor.

Active Duty servicemembers at three military sites - the Army Judge Advocate General School, the National Ground Intelligence Center, and the local Recruiting offices. Civilian sites range from a nearby community hospital to Habitat for Humanity. VANC's Paintings \& Prose: A Gallery of Possibilities serves as the prevocational trial site, with a fulltime VANC-employed vocational specialist (L. G. Leake). This combined art gallery/used bookstore allows servicemembers with TBI, PTSD, and cognitive and social difficulties to gradually reintroduce themselves back into a vocational situation in a supportive and closely supervised environment.

Paintings \& Prose operates on the historic downtown pedestrian mall in Charlottesville, Virginia, offering the real-life experiences of running a business and interacting with members of the community. The overall purpose of working at Paintings \& Prose is to provide a functional means to gain prevocational work skills for persons recovering from acquired brain injuries. The goal is to foster community integration and work reentry. Within this setting, therapeutic training and supervised work experience are provided in a supported work environment. Program participants strive to progress to more independent functioning, and hopefully, eventually seek employment in the community; or, in the 
case of military servicemembers, return to duty; or, for National Guard or Reserves members, return to their pre-Active Duty civilian jobs.

Job skill reacquisition is achieved through proven operant conditioning and cognitive-behavior therapies. Providing prompts to reshape behaviors and checklists to compensate for memory problems in the context of a socially positive environment are key to the program's success. The therapeutic objectives of a vocational trial at Paintings \& Prose include (1) prevocational assessment, (2) career exploration, (3) situational assessments, (4) job site assessment, (5) on-the-job cognitive strategies training, (6) work adjustment training, and (7) supervised work experience. Admission criteria for entering this vocational program include (1) completion of basic therapies, (2) a desire to work, (3) an ability to tolerate a minimum of 2 to 3 hours of continuous activity, (4) an ability to comply with attendance requirements, and (5) a practitioner or DRS referral.

Return to work is stressed by having participants learn and practice multiple and varied art gallery/ bookstore tasks, from installing art exhibits and stocking and sorting incoming books to eventually selling art and books to customers. A progressive hierarchy of tasks is used to guide program participants through fundamental tasks (e.g., recognizing titles and authors) to more sophisticated tasks (e.g., subdividing books into specialized areas).

As a retail business with a nonprofit status, Paintings \& Prose is supported by the community as well as VANC staff. Books are donated by the community and art pieces displayed are from the community of artists, including program participants, community members, and/or nationally and internationally renowned artists who contribute to themed art exhibits throughout the year.

Volunteer job opportunities at the art gallery/bookstore for recovering participants include (1) bookstore management, (2) front desk sales, (3) merchandising and display, (4) sorting and shelving, (5) processing donated books, (6) creating title categories, (7) searching rare book titles, and (8) installing art. Bookstore management duties include practicing a seven-step protocol for opening and closing the art gallery/bookstore, as well as daily cleaning and recovery of books for the store. Front desk sales duties include practicing an 11-step protocol for selling books, art, and music; greeting customers; and offering information about the art gallery/bookstore. Other aspects of front desk sales involve awareness of operating in a business environment (e.g., wearing clothes suitable to the public and being well groomed), maintaining the book cart (i.e., rolling the book cart outside when opening the store, retrieving it back into the store at the end of the day, and changing books on the cart weekly), maintaining the front desk itself (e.g., keeping the desk orderly and free of food or drink), and watering the plants at established intervals. Selling books requires making change, writing a receipt, bagging the book, and recording the title sold.

Merchandising and display job duties include (1) arranging the window display with books and art, (2) changing posted notices, and (3) arranging the book cart for outdoor sales. Sorting and shelving duties include (1) sorting and separating books for shelving in appropriate sections, (2) placing books in proper sections, (3) shelving books in alphabetical order in hardbacks and paperbacks, and (4) replenishing shelves when books are sold.

Other jobs at Paintings \& Prose such as processing donated books, creating title categories, searching rare book titles, and installing art all have relevant tasks broken into individual elements that are specific in nature. In this manner, each job is task analyzed so that individual elements can be shaped (i.e., developed) as needed and feedback provided until they are all brought together successfully.

Checklists aid in tracking completion of each job element and serve to encourage other compensatory strategies for executive function improvement as recovery progresses. For example, the checklist for opening the store includes (1) turning on the lights throughout the store, (2) turning on the radio/music, (3) placing the sign board on the mall, (4) rolling the book cart outside, (5) changing the "open" sign on door, (6) placing the cashbox in the sales desk, and (7) counting the currency in the cashbox and recording the amount in the sales ledger. A detailed shift report checklist comprehensively includes all tasks and sequences steps needed to successfully complete the jobs needed for the day. 
Whether military servicemembers or local civilians, brain injury survivors enter the prevocational program at Paintings \& Prose by first choosing a job, then cross-training in all jobs gradually, while using the traditional rehabilitation method of "practice-practicepractice." Successes on the job are recorded via checklists and medical chart notes for each participant. Working at Paintings \& Prose helps each person learn to run a small business, develop and sharpen skills in a supported prevocational workplace, and build their confidence by performing tasks in an environment designed for recovery of self-esteem and confidence by promoting a high probability of success. Skills are gradually redeveloped through behavioral models that are well proven to be effective.

Art plays an important role in the VANC program, as a social, therapeutic, integrative, and instructional medium. While the psychological value of the expressive arts has long been a therapeutic focus, modern neuroscience suggests the visual arts may provide special benefit for individuals recovering from brain injury [5]. VANC program participants have the opportunity to receive art instruction through artist Florence Hauser, a teacher and medical illustrator who volunteers her weekly lesson time. The program has numerous art supplies for expression through diverse media and even provides a mat cutter and mats for professional mounting of participant drawings for display.

In early 2008, artist and curator Dorothy Palanza volunteered her service to reestablish the gallery component of Paintings \& Prose. An experienced designer, Palanza converted the downtown space into a dynamic, contemporary gallery with seven exhibit areas, maintaining both the functionality of the used bookstore and the number of volumes on the shelves. A primary focus of the gallery is to provide a professional forum for integrated shows by artists with and without disabilities. The disclosure of one's disability status is entirely voluntary. Each artist determines what is important to include in his or her biographical statement. As curator Palanza notes, "visual art is a personal dialogue between the artist and the viewer. Art is able to relay messages where disability may or may not be an issue-everyone creates in their own way."
Thus far, the gallery has hosted three significant shows, including an initial international exhibit focusing on women's issues that later traveled to the Frauenmuseum in Bonn, Germany. Artists from Germany, Japan, Italy, and the United States volunteered their time and work to ensure the gallery reopening would be highly regarded and to establish the venue in the local arts community. The second show was a fully integrated exhibit prominently featuring members' work, timed for the arrival of friends and family during the holiday season. The most recent group show of assemblages highlights the work of Dr. Richard Bay, an artist, professor, and survivor of brain surgery. Each exhibit has included a traditional opening night, where hundreds of members of the Charlottesville community enjoy hors d'oeuvres, view the art, and converse with program participants and staff. The art gallery component of the program serves as a forum for equality, diversity, and celebration of each individual.

The VANC vocational program also includes other work sites in the community. In an effort to match vocational trials to individual preferences in the program, VANC enlists other community organizations to support over 20 other jobs. For example, arrangements with the local community hospital (located one block away from the Grove House) have resulted in vocational trials in food preparation and kitchen operations; dining room setup; environmental control; kitchen inventory; building maintenance; heating, ventilation, and air conditioning systems maintenance; information desk; customer service; computer service and repair; medical imaging; human resources; and certified nursing assistance and nursing. Other volunteer job sites in the local community include working as a personal training assistant at Gold's Gym; as a gallery guide at the Children's Discovery Museum; at other jobs at the Downtown Soup Kitchen, a real estate and brokerage company, Crutchfield's Electronics, Dive Connections, Atlas Comics, Habitat for Humanity, the Thomas Jefferson Area Food Bank, and the Music Resource Center; and as a teacher's assistant in a local preschool. For participants entering the program with more severe PTSD, initial roles may involve on-site jobs, such as grounds manager, at the Grove House. 
VANC seeks to provide services to civilians and military servicemembers with brain injuries by filling a gap in the traditional rehabilitative process between postacute hospitalization and a sometimes premature return to duty or home (e.g., National Guard). A major feature of the VANC program is the provision of vocational trials and a focus on positive, productive activity. All jobs are volunteer positions, but as with gainful employment, they do involve a job application and an interview process. Job orientation and training is provided on site. Job descriptions are typically provided by each job site. To help with future vocational pursuits, letters of recommendation are written for all individuals who complete their vocational trials. Perhaps most importantly, participants' confidence is reestablished through success and a sense of satisfaction by practicing new and relearned skills in a community-integrated setting.

\section{ACKNOWLEDGMENT}

We would like to thank photographer Rachael Nidiffer for the photographs of Painting \& Prose: A Gallery of Possibilities.

\section{REFERENCES}

1. Martin EM, Lu WC, Helmick K, French L, Warden DL. Traumatic brain injuries sustained in the Afghani- stan and Iraq Wars. Am J Nursing. 2008;108(4):40-47. [PMID: 18367927]

2. Pascrell B. Funding for the "Signature Injury" of the war in Iraq is key [Internet]. Washington (DC): Congressman Bill Pascrell; 2007 Mar 25 [2009 Jul 21]. Available from:

www.pascrell.house.gov/news/opeds.shtml/.

3. America's Heroes At Work. Why does employment play such an important role in the recovery of returning service members with TBI? [Internet]. Washington (DC): America's Heroes At Work; 2009 [2009 Jul 21]. Available from: http://www.americasheroesatwork.gov/resources/.

4. Ashley MJ, Ninomiya J, Berryman A, Goodwin K. Vocational rehabilitation. In: Ashley MJ, editor. Traumatic brain injury: Rehabilitative treatment and case management. 2nd ed. Boca Raton (FL): CRC Press; 2004.

5. Belkofer CM, Konopka LM. Conducting art therapy research using quantitative EEG measures. Art Therapy. 2008;25(2):56-63.

F. Don Nidiffer, PhD; ${ }^{1-3^{*}}$ L. G. Leake, MEd; $;^{1-2}$ Tina M. Trudel, PhD; ${ }^{1-4}$ Dorothy Palanza, MFA

${ }^{1}$ Defense and Veterans Brain Injury Center, Virginia NeuroCare, Charlottesville, VA; ${ }^{2}$ Mentor ABI Network, Boston, MA; ${ }^{3}$ University of Virginia Medical School, Charlottesville, VA; ${ }^{4}$ Lakeview Neurorehabilitation Centers, Effingham, NH; ${ }^{5}$ Colorfields Studio, Provincetown, MA

*Email: fdn@virginia.edu

DOI:10.1682/JRRD.2009.08.0114 